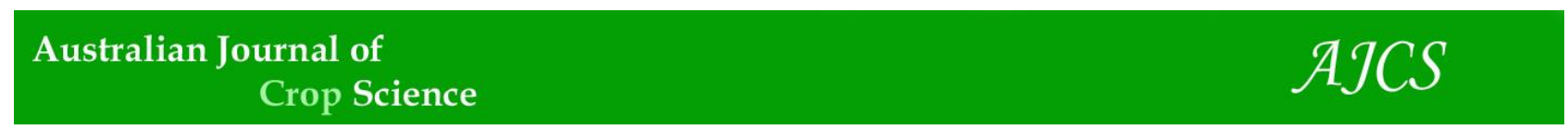

AJCS 15(08):1089-1094 (2021)

ISSN:1835-2707

doi: 10.21475/ajcs.21.15.08.p2638

\title{
Fertilizing model for Djulis (Chenopodium formosanum Koidz.) using mixture design approaches
}

\author{
Chien-Chang Chiu**1, Hung-Sheng Peng**2, Ching-Ying Liao ${ }^{3}$, Yu-Chu Chen ${ }^{3}$, Chong-Ho Wang ${ }^{1 *}$ \\ ${ }^{1}$ Department of Plant Industry, National Pintung University of Science and Technology. Pintung County, Neipu \\ Township, 1 Shueifu Road, 912 Taiwan \\ ${ }^{2}$ Department of Horticulture, National Taitung College. Taitung City, 889 ChengChi North Road, 950 Taiwan \\ ${ }^{3}$ Taitung District Agricultural Research and Extension Station, Council of Agriculture, Executive Yuan. Taitung city \\ 675 Chunghua Road Sec1, 950 Taiwan
}

*Corresponding author: chwang@mail.npust.edu.tw; **Equally first authors

\begin{abstract}
Djulis (Chenopodium formosanum Koidz.), a cereal plant native to Taiwan, was used for wine making, insect repellant, and health promotion. Therefore, using appropriate experimental design and modeling approach is of importance to predict the effect of the interaction among nitrogen $(\mathrm{N})$, phosphorus $(\mathrm{P})$, and potassium $(\mathrm{K})$ on djulis yields. In this study, a mixture design approach was applied to investigate the effects of interactions among nitrogen, phosphorus and potassium on the grain yields of djulis plants. Based on a three-variable including $\mathrm{N}, \mathrm{P}$, and $\mathrm{K}$ with each maximum of them was of $200 \mathrm{~g}\left(6 \mathrm{~m}^{2}\right)^{-1}$, a mixture design approach was employed by 42 experiments in 14 study plots to obtain an optimal combination of $\left.\mathrm{N}: \mathrm{P}: \mathrm{K}=100: 200: 100\left(\mathrm{~g} / 6 \mathrm{~m}^{2}\right)^{-1}\right)$ to predict an optimal dry djulis yield of $52.80 \mathrm{~g} /$ plant in this study. This study revealed that the linear mixture of $\mathrm{N}, \mathrm{P}$, and $\mathrm{K}$ and the interaction of $\mathrm{P}$ and $\mathrm{K}$ had marked effects on the yields of djulis. Moreover, the results were fitted to a quadratic polynomial equation using a multiple regression analysis. Our data showed this mixture design is a reliable approach to develop a model that can be used to predict the djulis yields.
\end{abstract}

Keywords: Chenopodium formosanum Koidz.; mixture design approaches; multiple regression analysis; left out test; Djulis. Abbreviations: DFFITS-Difference in fit standardized; ICP-MS-inductively coupled plasma-mass spectrometry.

Introduction

Djulis (Chenopodium formosanum Koidz.) is a native crop plant to Taiwan and, mostly, was used for wine making, insect repellant (Chio and Yang, 2008), and health promotion. The important compound of djulis was betalains and was reported recently on its antioxidant and anti-tuber bioactivities (Chyau et al. 2015; Khan and Giridhar, 2015; Tsai et al., 2010). In 2017, the djulis cultivation area in Taitung County was about 200 ha and the production was about 300 tons. Nitrogen uptake in cassava tuber was significantly affected by interaction between $\mathrm{N}$ and $\mathrm{K}$ and might be suggested that nitrogen $(\mathrm{N})$ and potassium $(\mathrm{K})$ had a synergistic effect on the nutrient uptake of cassva (Thummanatsakun and Yampracha, 2018). Hou et al. (2019) reveal that an adequate amount of $\mathrm{K}$ from the exchangeable $\mathrm{K}$ pool in the soil is necessary, if $\mathrm{N}$ was to be used wisely and efficiently in rice production for achieving its full role in increasing grain yield. In the general mixture problem, the measured response is assumed to depend only on the proportions of the ingredients percent in the mixture and not on the amount of the mixture (Cornell, 2002). The reason for mixing together ingredients in experiments is to investigate whether there exists mixture of two or more ingredients that produce more product properties than obtained from single ingredient individually (Cornell, 2002). Traditionally, the models used in mixture experiments are Scheffé's canonical polynomials (Cornell, 2002) and is as follows:
$\mathrm{Q}(\beta, \mathrm{X})=\beta_{0}+\sum_{i=1}^{q} \beta_{i} X_{i}+\sum \sum_{i<j}^{q} \beta_{i j} X_{i} X_{j}+$ $\sum \sum \sum_{i<j<k}^{q} \beta_{i j k} X_{i} X_{j} X_{k}+\cdots$

Where the $\beta^{\prime}$ s are the models parameter coefficients and $X_{i}, X_{j}$, $X_{k}$ are original components. Mixture methods have been used to successfully optimize conditions in structural ceramics, antifreeze performances, rice noodle quality, self-compacting concrete, and ice cream manufacture (Coronado et al. 2014; BahramParvar et al. 2015; Shi et al. 2015; Loubes et al. 2016; Liu et al. 2016). In this study, a mixture method was applied to investigate the effects of proportional combinations of nitrogen $(\mathrm{N})$, phosphorus $(\mathrm{P})$, and potassium $(\mathrm{K})$ that would produce the optimal djulis yields.

\section{Results and discussion}

\section{Multi-regression tests}

The results of the mixture experiments to determine the effects of three variables on yields of djulis are shown in Table 1 . The variables include nitrogen $\left(X_{1}\right)$, phosphorus $\left(X_{2}\right)$, and potassium $\left(X_{3}\right)$. By applying a multiple regression analysis on the experimental data, the predicted canonical model was obtained using following polynomial function:

Dry-weight $=-8.58 X_{1}+60.27 X_{2}+38.22 X_{3}-2.35 X_{1} X_{2}+14.22$ $X_{1} X_{3}-49.33 X_{2} X_{3}$ 


\section{Model fitness}

The F-value of this model was 7.79 (Table 2), which implied that the model was significant and there was less than a $0.61 \%$ chance that a large F-value could occur due to random error. The p-value in the model was less than 0.05 , which confirms the adequacy of the quadratic model. The data in Table 2 indicated that djulis dry weight was affected by the linear combination of nitrogen $\left(X_{1}\right)$, phosphorus $\left(X_{2}\right)$, and potassium $\left(X_{3}\right)$ with their quadratic terms of $\left(X_{2} X_{3}\right)(p<0.05)$. Furthermore, the $X_{1}, X_{2}, X_{3}$, and $X_{2} X_{3}$ values were the main factors affecting the djulis grains dry weight.

\section{Model sensitivities}

A model sensitivity analysis $\left(R^{2}=0.8295\right.$; adjusted $R^{2}=0.7230$; predicted $R^{2}=0.5350$; adequate precision $=10.530 ; A A D(\%)=$ 2.91) revealed that the model fit reasonably close to the experimental values (Table 3). It is generally considered that an adequate precision value greater than 4 is desirable (Carpinteyro and Torres, 2013). In this study, the adequate precision value was 10.530 , which indicates that an adequate signal from this model can be used to steer the design space. The relationship between the actual response (experimental data) and the predicted values was displayed linearly. The predicted $R^{2}$ was 0.5350 , indicating that it agreed reasonably well with the adjusted $R^{2}$ value of 0.7230 .

The actual value and predicted value were shown in Table 4. A two-tailed independent t-test was performed to confirm the adequacy of the model tested in this study. The results showed that the experimental responses agreed closely with the predicted values $(p=0.99)$. The linearity between actual and predicted values was shown in Fig. 1.

\section{Optimization of the process}

The main objective of this study was to find the optimal combination conditions of nitrogen, phosphorus, and potassium that would give the optimal djulis yields. The 2D contour plots and 3D response surfaces were used to represent the regression functions. The $2 \mathrm{D}$ contour plots and $3 \mathrm{D}$ response surfaces showed the combinational effect of $\mathrm{N}, \mathrm{P}$, and $\mathrm{K}$ on the djulis yields and were shown Fig. 2 and Fig. 3.

The model predicted that the optimal combination of the variables in this study would be a nitrogen: phosphorus: potassium = 100: 200: $100 \mathrm{~g} /\left(6 \mathrm{~m}^{-2}\right)$., which together would result in a optimal djulis yields of $52.80 \mathrm{~g} /$ plant in dry weight. Under these optimal conditions, the experimental data demonstrated that maximum actual djulis yields was of $53.91 \mathrm{~g}$ / plant, which was greater than the predicted value (52.80 g / plant). The maximum experimental value was of $53.91 \mathrm{~g} /$ plant and the combination of the independent variables was an N: P: $k=100: 200: 100 \mathrm{~g} /\left(6 \mathrm{~m}^{-2}\right)$. This might come from some outliers in the repeated experiments. However, the statistical results in this study showed that the data confirmed that these conditions of $\mathrm{N}: \mathrm{P}: \mathrm{k}=100: 200: 100 \mathrm{~g} /\left(6 \mathrm{~m}^{2}\right)$ were optimal to produce a maximal djulis yield and near the maximum experimental value in this study.

Thummanatsakun and Yampracha (2018) and Hou et al. (2019) revealed that when the proportion of $\mathrm{N}$ and $\mathrm{K}$ was of $1: 1$ the yields of cassava and rice might reach an optimal high value. In this study, the data showed that when $\mathrm{N}: \mathrm{K}=1: 1$ the yields of djulis reached an optimal high value. It was in consistent to the reports of Hou et al. and Thummanatsakun and Yampracha.

According to the contour plots in Figure 2, each curve represents a region of constant response. A steep slope or curvature in the plot indicates the sensitivity of the response to a particular factor. The 3D figures in Figure 3 show no saddle points on the graphs, indicating that the maximum data point is stable. The results of this study show that the experimental responses were closely agree with predicted values. Meanwhile, the result confirmed that the conditions found in this study was optimal to get highest djulis yield.

\section{The left out test of the model}

DFFITS (Difference in fit standardized) was a diagnostic tool to show how influential a point was in a statistical regression. It was obtained when that point was left out of the regression and was calculated by dividing by the estimated standard deviation of the fit at that point:

DFFITS $=\left(y_{i}-y_{i o}\right) /\left[s_{i o} \times\left(h_{i i}\right)^{1 / 2}\right]$

where $y_{i}$ and $y_{i o}$ were the prediction for point $i$ with and without point $\mathrm{i}$ included in the regression, $\mathrm{s}_{\mathrm{io}}$ was the standard error estimated without the point in question, and $h_{i i}$ was the leverage for the point. For a perfect experimental design, the leverage for each point was $p / n$, the number of factors divided by the number of points.

When investigating those points, the DFFITS was suggested greater than the limit, $2 \times(p / n)^{1 / 2}$. The DFFITS was shown in Table 5. When the DFFITS value exceeded the limit and greater than 2, they were the most influential cases (Aboobacker and Chen, 2009; Meloun and Militký, 2001; Belsley et al., 1980). The data in Table 6 showed that the DFFITS value in run order of 5 and 12 were exceeded the limit of DFFITS and greater than 2 . The standard order 5 and 12 could be identified as powerful influence runs.

\section{Outlier detections}

The internally studentized residual quantifies how large the residuals were and was calculated by the residual divided by the estimated standard deviation of that residual.

The externally studentized residual was calculated by:

$t_{i}=\left(e_{i}\right) /\left[M E_{i} \times\left(1-h_{i i}\right)\right]^{1 / 2}$

where $e_{i}$ was the residual for the ith observation and $M_{S} E_{i}$ was the mean squared error for the regression model if the ith observation was left out.

The $h_{i i}$ and externally studentized residual $\left(t_{i}\right)$ were useful for detecting potential outliers that probably deserve additional attention. When $t_{i}$ was greater than 3 , the data may be identified as an outlier (Gary and Woodall, 2012). Therefore, when the model was applied, those cases must be watched carefully. The DFFITS value and externally studentized residual identified that run order 12 in Table 5 as an outlier and had significant higher predicted values than the actual responses.

\section{Limitation and applicability}

It is possible to use a model equation with a higher degree than the second-order; however, a second-order equation is useful because it has only one stationary point. If a poor fit is caused by third or higher order terms, the second-order model representation would be inadequate (Arshad and Gilmour, 2012).

\section{Materials and Methods}

\section{Soil}

The average mineral contents in the planted soil were measured using an inductively coupled plasma-mass spectrometry (ICPMS) by Taitung Agricultural Research and Extension Station, Council of Agriculture, Executive Yuan, Taiwan and were of (in $\mathrm{mg} / \mathrm{kg}$ of soil) $\mathrm{P}_{2} \mathrm{O}_{5}: 19.60 \pm 1.03 ; \mathrm{K}_{2} \mathrm{O}: 80.54 \pm 4.12 ; \mathrm{CaO}$ : 
Table 1. Mixture design arrayfor djulis (Chenopodium formosanum Koidz.) yields.

\begin{tabular}{|l|c|c|c|c|}
\hline Run & Nitrogen & Phosphorus & Potassium & Yields (g/plant) \\
\hline 1 & $0^{+}$ & 1 & 1 & 48.4 \\
\hline 2 & 0.5 & 0.5 & 1 & 46.17 \\
\hline 3 & 0.5 & 1 & 0.5 & 53.91 \\
\hline 4 & 1 & 1 & 0 & 49.38 \\
\hline 5 & 1 & 0.5 & 0.5 & 36.38 \\
\hline 6 & 0.333 & 0.833 & 0.833 & 52.2 \\
\hline 7 & 0.5 & 0.5 & 1 & 46.17 \\
\hline 8 & 0 & 1 & 1 & 48.4 \\
\hline 9 & 0.833 & 0.333 & 0.833 & 41.23 \\
\hline 10 & 0.833 & 0.833 & 0.333 & 43.53 \\
\hline 11 & 1 & 1 & 0 & 49.38 \\
\hline 12 & 0.667 & 0.667 & 0.667 & 37.5 \\
\hline 13 & 1 & 0 & 1 & 43.6 \\
\hline 14 & 1 & 0 & 1 & 43.6 \\
\hline
\end{tabular}

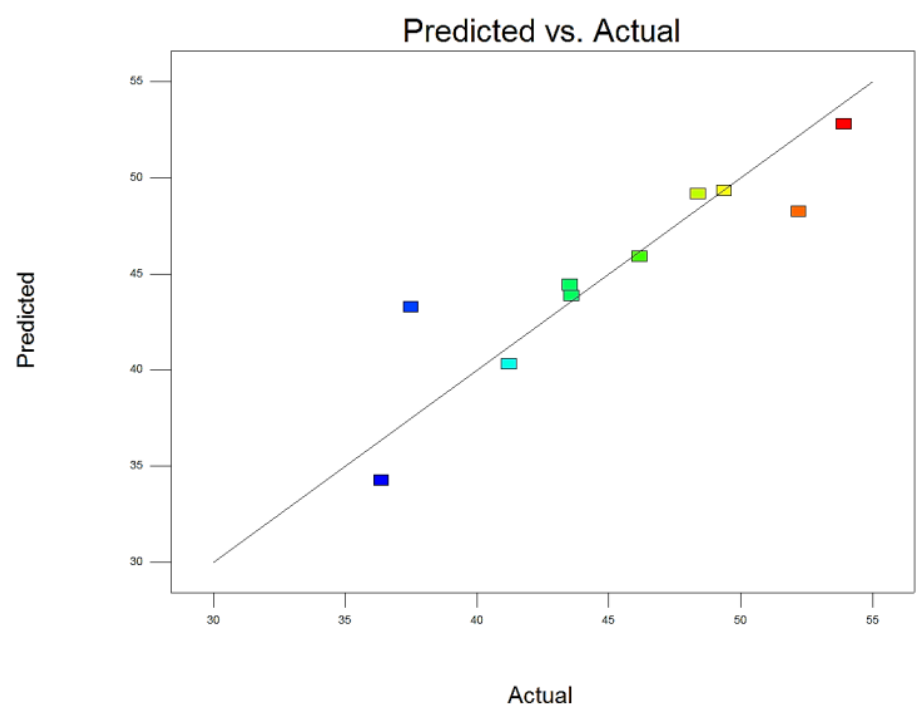

Fig 1. Linearity between actual and predicted responses.

Table 2. ANOVA for mixture factorsthat affected the yields of Chenopodium formosanum Koidz.

\begin{tabular}{|l|c|c|c|c|c|}
\hline Source & $\begin{array}{c}\text { Sum of } \\
\text { Squares }\end{array}$ & df & $\begin{array}{c}\text { Mean } \\
\text { Square }\end{array}$ & FValue & p-value \\
\hline Model & 281.52 & 5 & 56.30 & 7.79 & 0.0061 \\
\hline Linear Mixture & 118.67 & 2 & 59.34 & 8.20 & 0.0115 \\
\hline AB & 0.51 & 1 & 0.51 & 0.071 & 0.7965 \\
\hline AC & 13.05 & 1 & 13.05 & 1.80 & 0.2160 \\
\hline BC & 157.06 & 1 & 157.06 & 21.72 & 0.0016 \\
\hline
\end{tabular}

${ }^{\dagger} \mathrm{A}$ : nitrogen, B: phosphorus, C: potassium. ¥ The major factors of this study were linear mixture and the interaction of phosphorous and potassium

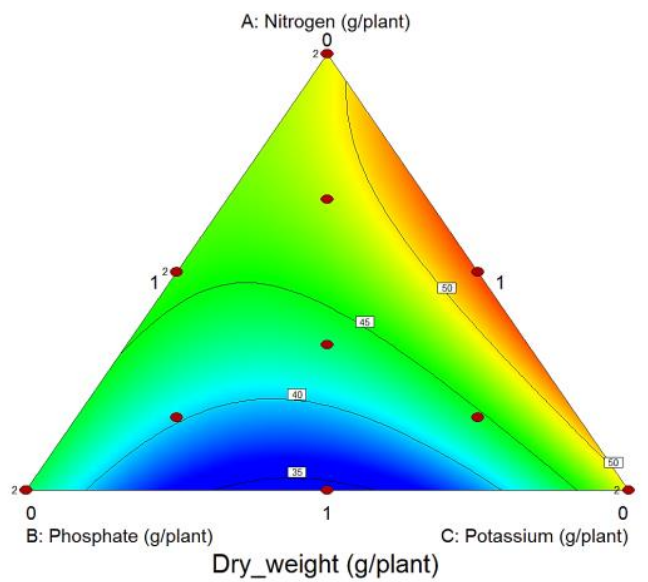

Fig 2. Contour plot of the mixture factors effect on the yields of djulis in dry weight. The red color region approaches higher yields and blue color region approaches lower yields. 
Table 3. Analysis of variance (ANOVA) for the fitted quadratic polynomial model of the strawberry fruit weight.

\begin{tabular}{|c|c|c|c|c|c|c|c|}
\hline $\begin{array}{l}\text { Standard } \\
\text { deviation }\end{array}$ & Mean & C.V.\% & $\mathrm{R}^{2}$ & Adjusted $R^{2}$ & $\begin{array}{l}\text { Predicted } \\
\mathrm{R}^{2+}\end{array}$ & $\begin{array}{l}\text { Adequate } \\
\text { precision }^{\ddagger}\end{array}$ & AAD (\%) \\
\hline 2.690 & 45.700 & 5.880 & 0.830 & 0.723 & 0.535 & 10.530 & 2.91 \\
\hline
\end{tabular}

${ }^{+}$Predicted $\mathrm{R}^{2}$, calculated by $\left\{1-\left[\Sigma\left(\mathrm{y}_{\text {iexp }}-\mathrm{y}_{\mathrm{ipre}}\right)^{2} / \mathrm{SS}_{\mathrm{T}}\right]\right\}$, where $\mathrm{y}_{\text {iexp }}$ is the experimental value, $\mathrm{y}_{\mathrm{ipre}}$ is the predicted value, and $\mathrm{SS}_{\mathrm{T}}$ is the corrected total. ${ }^{\ddagger} \mathrm{Adequate}$ precision, the signal to noise ratio.

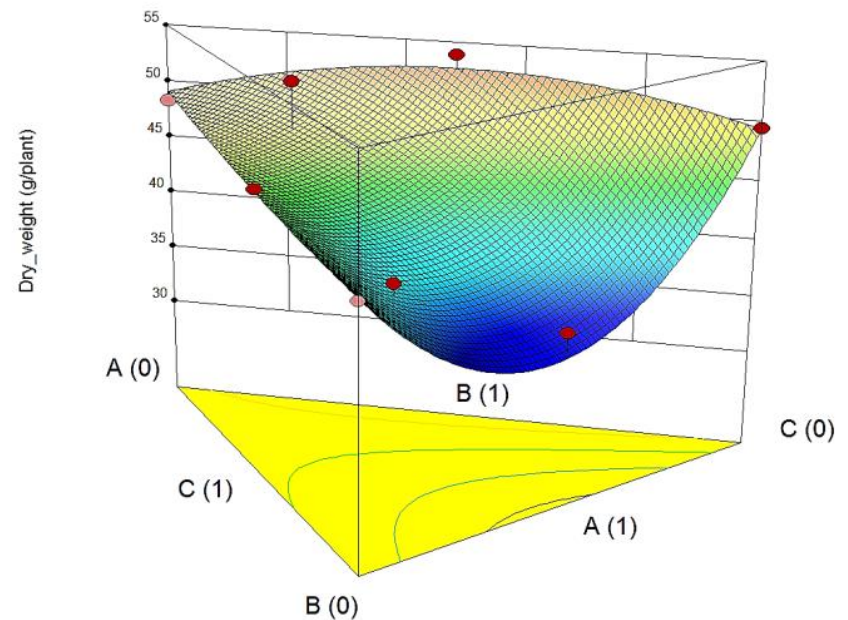

Fig 3. 3D graphs of the mixture factors affected the yields in dry weight. The pink spot is the design point below predicted value and the red spot is the design point above predicted value. Where A: Nitrogen, B: Phosphorus, C: Potassium.

Table 4. Actual value vs. Predicted value.

\begin{tabular}{|l|c|c|}
\hline Run Order & Actual Value & PredictedValue \\
\hline 1 & 48.40 & 49.16 \\
\hline 2 & 46.17 & 45.92 \\
\hline 3 & 53.91 & 52.80 \\
\hline 4 & 49.38 & 49.33 \\
\hline 6 & 36.38 & 34.26 \\
\hline 7 & 52.20 & 48.25 \\
\hline 8 & 46.17 & 45.92 \\
\hline 9 & 48.40 & 49.16 \\
\hline 10 & 41.23 & 40.30 \\
\hline 11 & 43.53 & 44.42 \\
\hline 12 & 49.38 & 49.33 \\
\hline 14 & 37.50 & 43.29 \\
\hline
\end{tabular}

Table 5. Diagnostic case statistics of djulis(Chenopodium formosanum Koidz.)yields in difference in fit.

\begin{tabular}{|c|c|c|c|c|c|c|}
\hline $\begin{array}{l}\text { Runs } \\
\text { Order }\end{array}$ & Residual & Leverage & $\begin{array}{l}\text { Internally } \\
\text { Studentized } \\
\text { Residual }\end{array}$ & $\begin{array}{c}\text { Externally } \\
\text { Studentized } \\
\text { Residual }\end{array}$ & $\begin{array}{c}\text { Cook's } \\
\text { Distance }\end{array}$ & $\begin{array}{c}\text { Influence on } \\
\text { Fitted Value } \\
\text { DFFITS }\end{array}$ \\
\hline 1 & -0.76 & 0.482 & -0.392 & -0.370 & 0.024 & -0.357 \\
\hline 2 & 0.25 & 0.423 & 0.123 & 0.116 & 0.002 & 0.099 \\
\hline 3 & 1.11 & 0.715 & 0.774 & 0.753 & 0.250 & 1.192 \\
\hline 4 & 0.049 & 0.481 & 0.025 & 0.023 & 0.000 & 0.023 \\
\hline 5 & 2.12 & 0.715 & 1.476 & 1.618 & 0.911 & $2.564 *$ \\
\hline 6 & 3.95 & 0.195 & 1.637 & 1.877 & 0.108 & 0.925 \\
\hline 7 & 0.25 & 0.423 & 0.123 & 0.116 & 0.002 & 0.099 \\
\hline 8 & -0.76 & 0.482 & -0.392 & -0.370 & 0.024 & -0.357 \\
\hline 9 & 0.93 & 0.195 & 0.384 & 0.362 & 0.006 & 0.179 \\
\hline 10 & -0.89 & 0.222 & -0.377 & -0.356 & 0.007 & -0.190 \\
\hline 11 & 0.049 & 0.481 & 0.025 & 0.023 & 0.000 & 0.023 \\
\hline 12 & -5.79 & 0.223 & -2.441 & $-4.517 * *$ & 0.285 & $-2.420 *$ \\
\hline 13 & -0.25 & 0.482 & -0.131 & -0.123 & 0.003 & -0.119 \\
\hline 14 & -0.25 & 0.482 & -0.131 & -0.123 & 0.003 & -0.119 \\
\hline
\end{tabular}

$\dagger^{*}$ Exceed limits (when DFFIT value was greater more than 2 , the runs may have power to influence model result). $¥$ When externally studentized residual is greater than 3 , the data was identified as an outlier. 
$770.63 \pm 4.50$; MgO: $154.39 \pm 7.02$; Fe: $39.8 \pm 8.58$; Mn: $39.90 \pm$ 6.32. The organic compounds content and $\mathrm{pH}$ value of the soil were of $3.72 \pm 0.45 \%$ and $5.39 \pm 0.09$ respectively.

The straight fertilizers including $\mathrm{N}, \mathrm{P}_{2} \mathrm{O}_{5}$, and $\mathrm{K}_{2} \mathrm{O}$ were bought from Taiwan Fertilizer Company LTD., Taiwan.

\section{Djulis seedlings}

The $35 \mathrm{~cm}$ height djulis seedlings were collected from the Taitung Agricultural Research and Extension Station, Council of Agriculture, Executive Yuan, Taiwan.

\section{Mixture Experimental design}

The mixture experiments are Scheffé's canonical polynomials (Cornell, 2002). Scheffé's Cubic Model was listed in Introduction section.

When levels of factors in an experiment were changed, it could affect the mixing properties of the ingredients. Fourteen $2 \mathrm{mx}$ $3 \mathrm{~m} \times 35 \mathrm{~cm}$ square plots were made and each plot was separated by $3 \mathrm{~m}$. Ten djulis seedlings were planted along the fringe on each plot and each seedling was separated by $1 \mathrm{~m}$. Fertilizer mixtures were made according to the mixture design array (Table 1) and the fertilizers were sprayed averagely on the middle line of each plot once only from the seedling were planted to harvested.

This study were conducted from November to March next year and were from 2014 to 2017, respectively. The djulis were harvest on March and was dried in sun and the dry weight were measured each year.

Mixture method was used to determine the mixture effects of the variables including nitrogen $(N)$, phosphorus $(P)$, and potassium (K) and all in $\mathrm{g} /\left(6 \mathrm{~m}^{2}\right)$. The coded mixture variables used in the mixture method design were listed in Table 1 . The maximum weight of fertilizers that combined with $\mathrm{N}, \mathrm{P}$, and $\mathrm{K}$ was $600 \mathrm{~g} /\left(6 \mathrm{~m}^{2}\right)$. A three-variable and fourteen runs were applied to investigate the best portion combination of $\mathrm{N}, \mathrm{P}$, and $K$ that would reach highest djulis yields. The study were repeated three times.

\section{Adequacy tests}

The significant terms were found using an analysis of variance (ANOVA) for each response and were subjected to an F-test at a probability level less than 0.05 .

Baş and Boyaci (2007) reported that a large total determination coefficient value $\left(R^{2}\right)$ does not necessarily imply that the regression model is adequate. The addition of variables always increases $R^{2}$ regardless of whether the added variables are statistically significant. The application of the absolute average deviation (AAD) can eliminate these types of errors. The AAD is calculated using the following equation:

$\mathrm{AAD}=\left\{\left[\sum_{i=1}^{p}\left(\left|y_{i \exp }-y_{i p r e}\right|\right) / y_{i \exp }\right] / \mathrm{P}\right\} \times 100$

where $y_{\text {iexp }}$ represents the experimental value, $y_{\text {ipre }}$ represents the predicted value, and $\mathrm{P}$ represents the number of runs.

\section{Sensitivities tests}

In total, the model was evaluated using the $R^{2}$, adjusted- $R^{2}, A A D$, and adequate precision values. A good model generally has a high $R^{2}$, a low $A A D$, and a high adequate precision value.

The $R^{2}$ value is the coefficient of determination and is calculated by $\Sigma\left(y_{\text {ipre }}-\mathrm{y}_{\text {avg }}\right)^{2} / \mathrm{SS}_{T}$, where $y_{\text {ipre }}$ is the predicted value, $\mathrm{y}_{\text {avg }}$ is the average value, and $\mathrm{SS}_{\mathrm{T}}$ is the corrected total which generally equals to the total of the sum of squares of both model and residual. The $\mathrm{R}^{2}$ is always positive. The higher is the coefficient of determination, the better the variance that the dependent variable is explained by the independent variable. The coefficient of determination is the overall measure of the usefulness of a regression.

. The adjusted $R^{2}$ value is calculated by $\{1-[(n-1) /(n-p)] \times(1$ $\left.\left.-R^{2}\right)\right\}$, where $n$ represents the observations and $p$ represents the number of parameters. The predicted $R^{2}$ is calculated by $\{1-[\Sigma$ $\left.\left.\left(\mathrm{y}_{\text {iexp }}-\mathrm{y}_{\text {ipre }}\right)^{2} / \mathrm{SS}_{\mathrm{T}}\right]\right\}$, where $\mathrm{y}_{\text {iexp }}$ represents the experimental value, $y_{\text {ipre }}$ represents the predicted value, and $\mathrm{SS}_{\mathrm{T}}$ represents the corrected total that generally equals the sum of the model squares and residual squares. $\mathrm{SS}_{\mathrm{T}}$ represents the sum of squares that was not calculated from zero, but was instead corrected by summing the squared distances of each individual response value from its entire average. Totally, predicted $R^{2}$ represents the predictive capacity of the model.

The adequate precision value is the signal-to-noise ratio and is calculated by

$$
\left[(\operatorname{Max}(Y P)-\operatorname{Min}(Y P)] /\left(p \sigma^{2} / n\right)^{1 / 2}\right.
$$

Where YP is the predicted values at the run settings, $p$ is the parameters (including intercept $\left(\beta_{0}\right)$ and any block coefficients) number of the model, $\sigma^{2}$ is the residual mean square from ANOVA table, and $\mathrm{n}$ is the number of runs in the experiment.

\section{Statistics}

Design Expert Version 9 (Stat-Ease, USA) software was used to calculate the mixture method design in this study. A two-tailed independent t-test in SPSS Version 22 (IBM SPSS, USA) was used to evaluate the significant difference between the experimental and predicted groups.

\section{Conclusion}

The djulis yields could be sufficiently described by the secondorder polynomial model generated in this study. The independent variables included nitrogen, phosphorus, and potassium can be estimated using the contour and 3D surface plots in mixture method design. Moreover, the graphical estimation method in mixture methodology was adopted to estimate the optimal djulis yields conditions. Following the optimal conditions, the mean experimental djulis yields were corresponded well with the predicted values. Therefore, the model generated in this study is an important tool for predicting djulis yields.

\section{References}

Aboobacker J, Chen J (2009) Assessing global influential observations in modified ridge regression. Stat Probabil Lett. 79: 513-518.

Arshad HM, Gilmour SG (2012) The performance of subset response surface designs for estimating third order terms. J Stat Plan Infer. 142: 232-247.

Baş D, Boyaci IH (2007) Modeling and optimization 1: usability of response surface methodology. Food Eng. 78: 836-845.

BahramParvar M, Tehrani MM, Razavi SMA, Koocheki A (2015) Application of simplex-centroid mixture design to optimize stabilizer combinations for ice cream manufacture. J Food Sci Tech. 52(3):1480-1488.

Belsley DA, Kuh E, Welsch RE (1980) Regression diagnostics identifying influential data and sources of collinearity. Wiley, Hobocon, NJ. 2. 
Carpinteyro US, Torres LG (2013) Use of response surface methodology in the optimization of coagulation flocculation of wastewaters employing biopolymers. Int J Environ Res. 7(3): 711-726.

Chio EH, Yang E C (2008) A bioassay for natural insect repellents. J Asia-Pac Entomol. 11: 225-227.

Chyau CC, Chu CC, Chen SY, Duh PD (2015) Djulis (Chenopodiun formosaneum) and its bioactive compounds protect against oxidative stress in human HepG2 cells. J Funct Food. 18: 159170.

Cornell J (2002) Experiments with mixtures: designs, models, and the analysis of mixture data. 3rd edn.. Wiley, New York. 2.

Coronado M, Segadães AM, Andrés A (2014) Combining mixture design of experiments with phase diagrams in the evaluation of structural ceramics containing foundry by-products. Appl Clay Sci. 101: 390-400.
Gary JB, Woodall WH (2012) The maximum size of standardized and internally studentized residual in regression analysis. Am Stat. 48(2): 111-113.

Hou W, Xue X, Li X, Khan MR, Yan J, Ren T (2019) Interactive effects of nitrogen and potassium on: grain yield, nitrogen uptake and nitrogen use efficiency of rice in low potassium fertility soil in China. Field Crop Res. 236: 14-23

Khan MI, Giridhar P (2015) Plant betalains: chemistry and biochemistry. Phytochenistry. 117: 267-295.

Liu Z, Sha A, He R, Xing M (2016) Antifreeze asphalt mixtures design and antifreeze performances prediction based on the phase equilibrium of natural solution. Cold Reg Sci Technol. 129: 104-113.

Loubes MA, Flores SK, Tolaba MP (2016) Effect of formulation on rice noodle quality: selection of functional ingredients and optimization by mixture design. LWT - Food Sci Technol. 69: 280-286. 